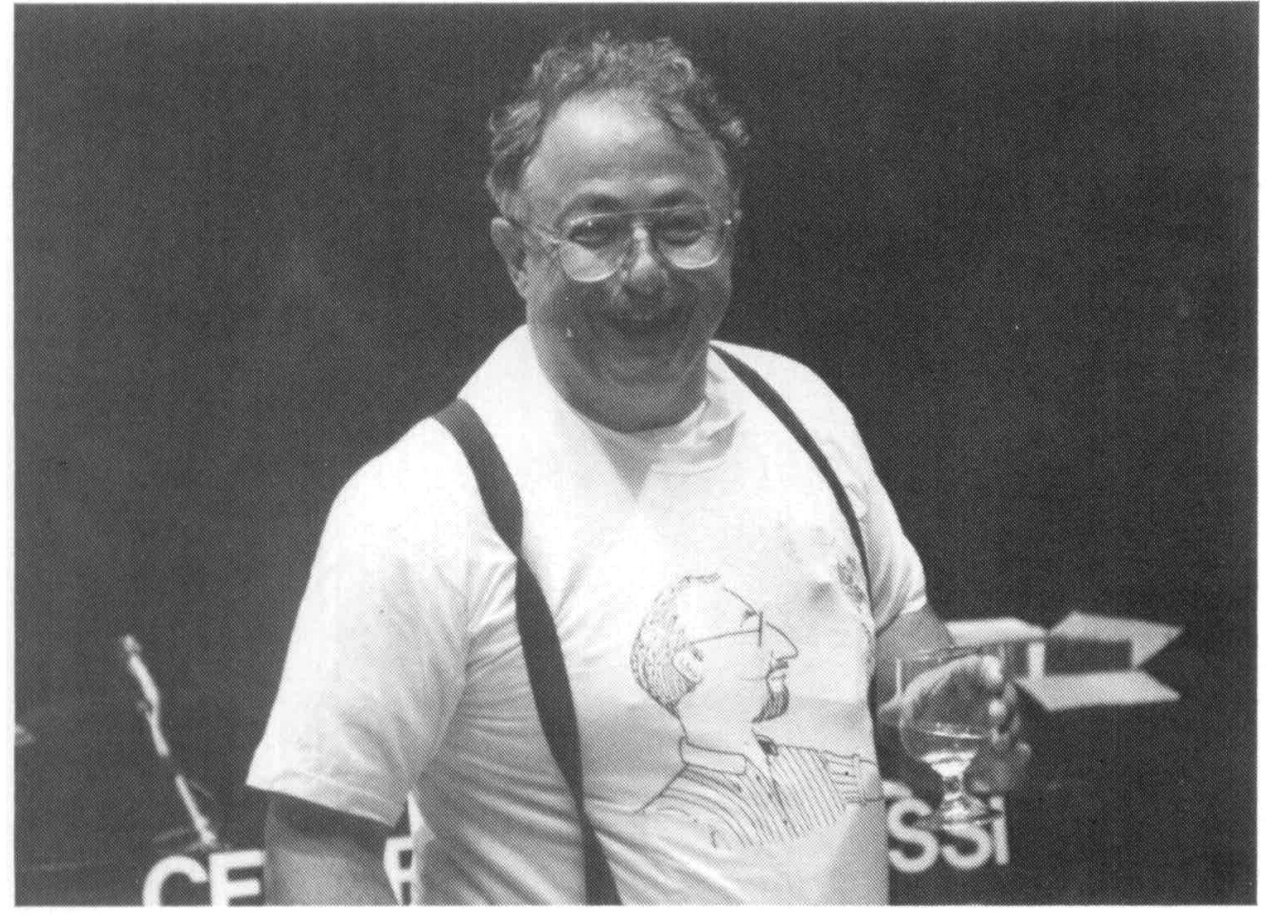

Master of Ceremonies, Jim Mayer, opens the meeting of the Boehmische Physical Society at IBMM' 86.

have ranged from sputter-induced topology ( $R$. Kelly) to hydrogen in glasses [including beer glasses) (W. Lanford).

At the IBMM ' 86 meeting in Catania on Tuesday evening, June 10,1986 , the preliminaries of the Boehmische meeting ran true to form. Master of ceremonies, Jim Mayer (Cornell University), a ppeared sporting a $T$-shirt adorned with a profile caricature of IBMM ' 86 chairman E. Rimini. A master of iconoclastic spellbinding anecdotes, Mayer proceeded to confer small tokens of appreciation on several in the audience who had recently been elevated or elected to positions requiring some form of recognition.

Representing somewhat of a topical de-

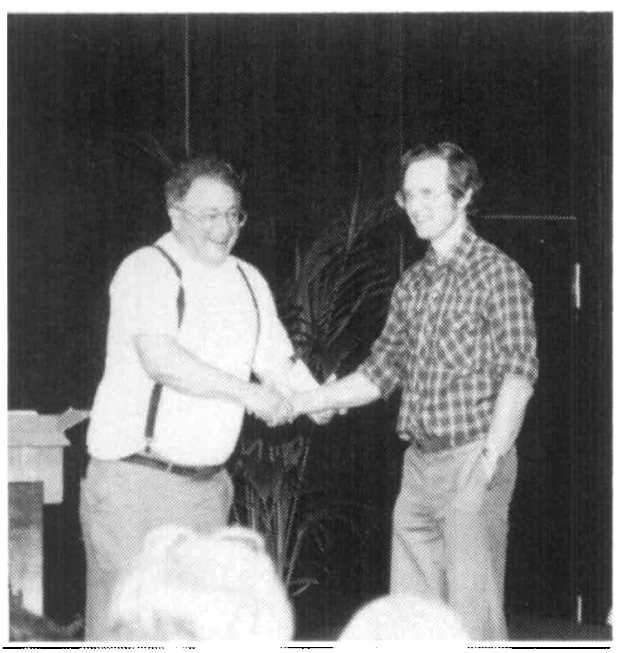

Jim Mayer (left) congratulates Jim Williams (RMIT, Australia) during Boehmische proceedings.

E. N. KAUFMANN

\section{Four Materials Conferences Held Recently in Taiwan}

Four scientific conferences were held earlier this year, drawing international scientists for discussions on composites, superalloys, and semiconductors.

The International Conference on Advanced Composite Materials and Structures held in Taipei, Taiwan, May 19-23, 1986 was jointly sponsored by the Chinese Society for Materials Science, the Society of Theoretical and Applied Mechanics in the Republic of China, and the Institute of Fracture and Solid Mechanics of Lehigh University. The conference chairmen were
Professor George C. Sih and Dr. Shu-En Hsu. Approximately 200 participants attended from the local area and abroad.

More than 70 papers were presented in the conference. The topics discussed were: (1) Static and dynamic resistance of composites to crack growth and other modes of damage;

(2) Thermodynamics and kinetics of processes at fiber-matrix interface and their effects on composite properties;

(3) Fatigue resistance and aging of composites in hostile environments;

(4) Vibrational damping characteristics in relation to composite microstructures and laminate structures;

(5) Application of composite data and specimen data to design of structural components;

(6) Predictive methodology for deformation and failure of composites;

(7) Analytical and numerical modeling of composite system behavior;

(8) Joining or bonding of composite components;

(9) Nondestructive evaluation of composite systems;

(10) Damage tolerance and inspection requirements for composites; and

(11) Materials science of composites.

Achievements in theoretical and applied research on modern advanced composite materials were presented at this successful conference.

A superalloy workshop was held at National Tsing Hua University, Hsinchu, Taiwan, May 29-30, 1986. More than 20 papers were presented, and intermetallic compound and IN-718 were emphasized at the workshop. Professor John Tien of Columbia University was the invited speaker.

The 1986 annual conference of the Chinese Society for Materials Science was held in Taiwan, Taiwan, June 20-21, 1986; and a workshop on Compound Semiconductor Science and Technology was held at National Chiao Tung University, Hsinchu, Taiwan, March 13-14, 1986.

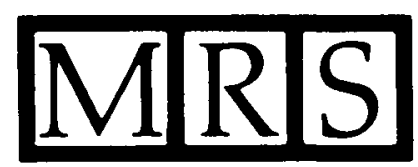

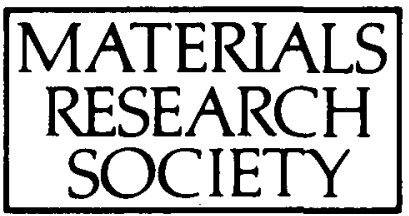

